Article

\title{
Catalytic Transfer Hydrogenation of Biobased HMF to 2,5-Bis-(Hydroxymethyl)Furan over $\mathrm{Ru} / \mathrm{Co}_{3} \mathrm{O}_{4}$
}

\author{
Ting Wang ${ }^{1}$, Junhua Zhang ${ }^{1,2, *}$, Wenxing Xie ${ }^{1}$, Yanjun Tang ${ }^{1}$, Daliang Guo ${ }^{1,3}$ \\ and Yonghao $\mathrm{Ni}^{2, *}$ \\ 1 Bioenergy \& Biomass Centre, National Engineering Laboratory of Textile Materials Processing Technology, \\ Zhejiang Sci-Tech. University, Hangzhou 310018, China; wting_5@163.com (T.W.); \\ 18720974664@163.com (W.X.); tangyj@zstu.edu.cn (Y.T.); guodl@zstu.edu.cn (D.G.) \\ 2 Department of Chemical Engineering, University of New Brunswick, Fredericton, NB E3B 5A3, Canada \\ 3 Key Laboratory of Pulp and Paper Science \& Technology of Ministry of Education of China, \\ Qilu University of Technology, Jinan 250353, China \\ * Correspondence: zhangjh@zstu.edu.cn (J.Z.); yonghao@unb.ca (Y.N.); Tel.: +86-571-8684-3871 (J.Z.); \\ +1-506-4516857 (Y.N.); Fax: +86-571-8684-3250 (J.Z.); +1-506-4534767 (Y.N.)
}

Academic Editors: Albert Demonceau, Ileana Dragutan and Valerian Dragutan

Received: 4 March 2017; Accepted: 16 March 2017; Published: 21 March 2017

\begin{abstract}
Bis-(hydroxymethyl)furan (BHMF) is an important biomass-based platform chemical that can be derived from the hydrogenation of biomass-based 5-hydroxymethylfurfural (HMF). In this paper, the formation of BHMF from HMF via the catalytic transfer hydrogenation (CTH) process, using isopropanol as the hydrogen source and $\mathrm{Ru} / \mathrm{Co}_{3} \mathrm{O}_{4}$ as the catalyst, was studied. The results revealed that the $\mathrm{Ru} / \mathrm{Co}_{3} \mathrm{O}_{4}$ catalyst displayed a high catalytic efficiency, and that a BHM yield of up to $82 \%$ was obtained at $190{ }^{\circ} \mathrm{C}$ in $6 \mathrm{~h}$. Moreover, it was found that the recovered $\mathrm{Ru} / \mathrm{Co}_{3} \mathrm{O}_{4}$ exhibited a similar catalytic activity to the pristine $\mathrm{Ru} / \mathrm{Co}_{3} \mathrm{O}_{4}$ catalyst. These results supported the conclusion that the present $\mathrm{CTH}$ process is an attractive green route for the synthesis of $\mathrm{BHMF}$ from biomass-based HMF.
\end{abstract}

Keywords: biomass; 5-hydroxymethylfurfural; 2,5-bis-(hydroxymethyl)furan; catalytic transfer hydrogenation; ruthenium based catalyst

\section{Introduction}

The development of efficient production technologies for biomass-based fuels and chemicals has received much attention [1,2]. In this context, 5-hydroxymethylfurfural (HMF), which was identified as a key precursor and called a "sleeping giant" for the synthesis of biofuels and high value-added chemicals, has been widely studied. As shown in Figure 1, HMF possesses two functional groups: an aldehyde and an alcohol, so it can be easily converted into value-added compounds to be used in a wide variety of chemical manufacturing applications and industrial products [3]. Importantly, HMF can be hydrogenated to 2,5-bis-(hydroxymethyl)furan (BHMF), which is a monomer for the synthesis of heat insulating material [4], resins, and crown ethers [5]. Moreover, BHMF is a promising diol that can be used either directly for the synthesis of shape memory and self-healing polymers or for the synthesis of 1,6-hexanediol, which is also an important polymer precursor [6].

Several studies reported the conversion of HMF to BHMF. For example, Kang et al. [7] reported that HMF is converted to BHMF via a Cannizzaro reaction using ionic liquids as a recyclable solvent under water-free conditions, and an excellent yield was obtained when [EMIm]TFSI was used as the solvent. Subbiah et al. [8] reported that a 40\% BHMF yield can be obtained through the Cannizzaro reaction of $\mathrm{HMF}$ using $\mathrm{NaH}$ in dry THF. Usually, 5-hydroxymethylfuranoic acid (HMFA) is also formed (in an equimolar amount) during the same course of Cannizzaro reactions, which results in 
challenges in the subsequent separation processes. In addition to the Cannizzaro reaction, the catalytic hydrogenation of HMF can lead to the formation of BHMF. Zhu et al. [9] reported a 99.1\% selectivity for the conversion of HMF to BHMF at $100{ }^{\circ} \mathrm{C}$ over $3 \mathrm{~h}$ of reaction in ethanol with $\mathrm{Cu}-\mathrm{ZnO}$ as the catalyst. Chatterjee et al. [10] reported that $\mathrm{Pt} / \mathrm{MCM}-41$ could be used as an efficient catalyst for the hydrogenation of HMF to BHMF, and $98.9 \%$ selectivity of BHMF was obtained at $35^{\circ} \mathrm{C}$ and $0.8 \mathrm{MPa}$ $\mathrm{H}_{2}$. In these studies, molecular hydrogen was used.

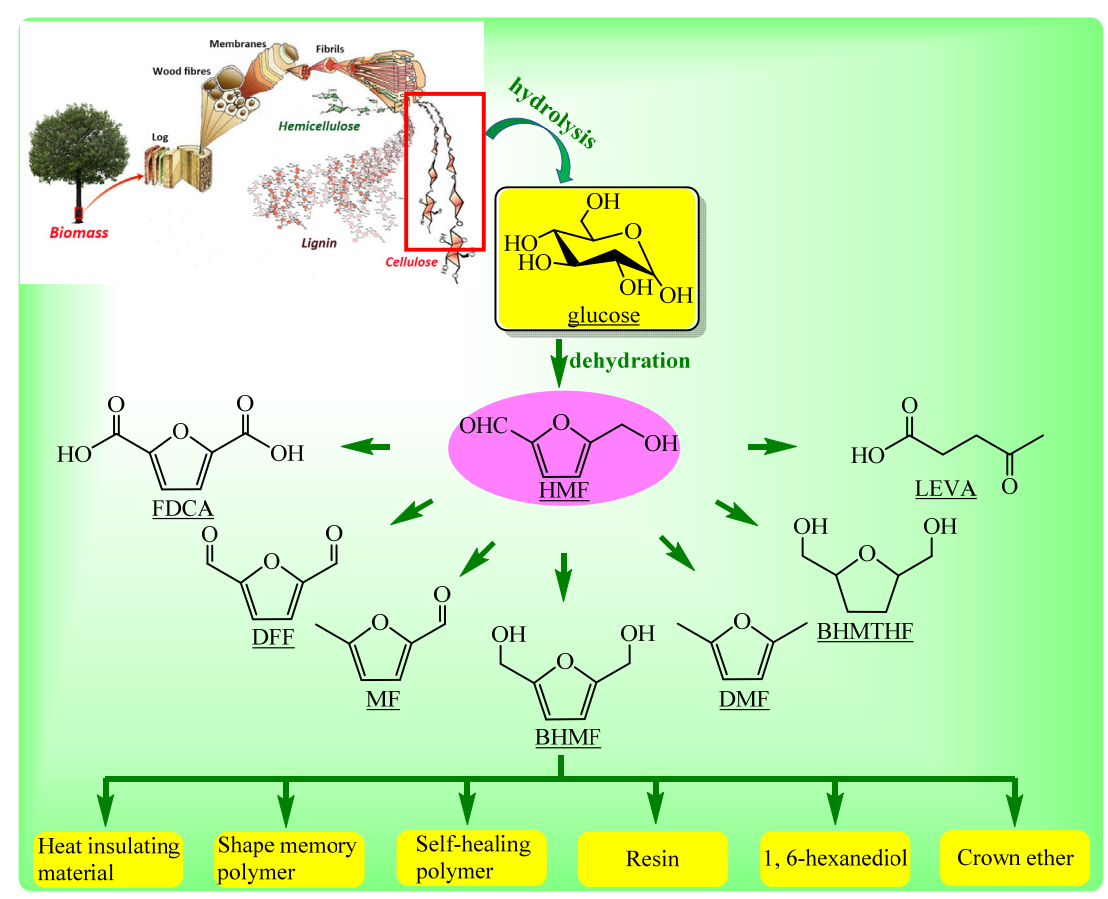

Figure 1. 2,5-Bis-(hydroxymethyl)furan (BHMF) is a biomass-based platform chemical, which can be made from 5-hydroxymethylfurfural (HMF).

The catalytic transfer hydrogenation $(\mathrm{CTH})$ process has been reported as an efficient and simple method for the reduction of biomass-derived chemicals in the absence of molecular hydrogen [11]. The $\mathrm{CTH}$ process can also be used for the hydrogenation of HMF to other high value-added chemicals, such as 2,5-dimethylfuran (DMF) [12]. Therefore, the CTH process may be an alternative for the conversion of HMF to BHMF if a suitable catalyst can be identified.

Ruthenium is a cost-effective noble metal for the catalytic hydrogenation reaction $[13,14]$. In the present work, $\mathrm{Ru} / \mathrm{Co}_{3} \mathrm{O}_{4}$ was prepared by a co-precipitation method and used as a catalyst for the CTH of HMF to BHMF, while isopropanol was used as the hydrogen donor. The study would be helpful in assessing the feasibility of $\mathrm{CTH}$ of $\mathrm{HMF}$ to $\mathrm{BHMF}$ in the presence of a $\mathrm{Ru} / \mathrm{Co}_{3} \mathrm{O}_{4}$ catalyst, which will provide a potential route for the green synthesis of BHMF from biomass-based materials.

\section{Results and Discussion}

\subsection{CTH of HMF to BHMF}

The detailed results regarding the effect of the reaction temperature and time are shown in Table 1. It was found that the effect of the reaction temperature on the CTH of HMF to BHMF is significant (Table 1, Entries 1-5). At $130^{\circ} \mathrm{C}$, only $37.1 \%$ of HMF was consumed, and the BHMF yield was $24.4 \%$. In contrast, the conversion reached $94.4 \%$ when the temperature was elevated to $170{ }^{\circ} \mathrm{C}$, and the BHMF yield was $80.3 \%$. When the temperature was further increased to $190^{\circ} \mathrm{C}$ and $210{ }^{\circ} \mathrm{C}$, no residual HMF was found; however, the BHMF yields were decreased to $79.3 \%$ and $67.7 \%$ due to the further hydrogenation of BHMF to 5-methyl furfuryl alcohol (MFA) (the MFA yield was $9.0 \%$ at $190{ }^{\circ} \mathrm{C}$, and 
$17.2 \%$ at $\left.210^{\circ} \mathrm{C}\right)$. In addition to the reaction temperature, the effect of the reaction time is also shown in Table 1 (Entries 4 and 6-7). As shown, the maximum BHMF yield of $82.8 \%$ was obtained with an HMF conversion of $100 \%$ at $6 \mathrm{~h}$, and no MFA was found. Upon further increasing the hydrogenation time, a small decrease in the BHMF yield was observed due to the further hydrogenation of BHMF to MFA, and a $7.7 \%$ and $9.0 \%$ MFA yield were found at $8 \mathrm{~h}$ and $10 \mathrm{~h}$, respectively.

Furthermore, the catalyst recovery experiment was also performed. In a typical recycling test, the catalyst was separated from the reaction mixture by filtration after reaction and dried at $105^{\circ} \mathrm{C}$ for $12 \mathrm{~h}$, followed by $\mathrm{NaBH}_{4}$ reduction. The result showed that the regenerated catalyst exhibited similar catalytic activity to that of the pristine catalyst, the BHMF yield reached 75.2\% with an HMF conversion of $95.3 \%$ at $170{ }^{\circ} \mathrm{C}$ in $10 \mathrm{~h}$, and a recovery efficiency of $94 \%$ (Table 1, Entry 8).

Table 1. Catalytic transfer hydrogenation (CTH) of $\mathrm{HMF}$ to $\mathrm{BHMF}$ in isopropanol using $\mathrm{Ru} / \mathrm{Co}_{3} \mathrm{O}_{4}$ as the catalyst (0.5 wt \% HMF, $0.25 \mathrm{wt} \% \mathrm{Ru} / \mathrm{Co}_{3} \mathrm{O}_{4}$ and $20 \mathrm{~mL}$ of isopropanol).

\begin{tabular}{|c|c|c|c|c|c|}
\hline \multirow{2}{*}{ Entry } & \multirow{2}{*}{$\mathrm{T}\left({ }^{\circ} \mathrm{C}\right)$} & \multirow{2}{*}{$t(h)$} & \multirow{2}{*}{ Conv. (\%) } & \multicolumn{2}{|c|}{ Yield \% } \\
\hline & & & & BHMF & MFA \\
\hline 1 & 130 & 10 & 37.1 & 24.4 & - \\
\hline 2 & 150 & 10 & 66.7 & 51.7 & - \\
\hline 3 & 170 & 10 & 94.4 & 80.3 & - \\
\hline 4 & 190 & 10 & 100 & 79.3 & 9.0 \\
\hline 5 & 210 & 10 & 100 & 67.7 & 17.2 \\
\hline 6 & 190 & 6 & 100 & 82.8 & - \\
\hline 7 & 190 & 8 & 100 & 79.9 & 7.7 \\
\hline $8^{*}$ & 170 & 10 & 95.3 & 75.2 & - \\
\hline
\end{tabular}

\section{2. $\mathrm{H}_{2}$-TPR Profiles}

The $\mathrm{H}_{2}$-TPR profiles of the three $\mathrm{Ru} / \mathrm{Co}_{3} \mathrm{O}_{4}$ catalysts (calcined, reduced and recycled $\mathrm{Ru} / \mathrm{Co}_{3} \mathrm{O}_{4}$ samples) are shown in Figure 2. As can be observed, the three catalysts are all displaying a two-stage reduction mechanism, and the first peak of each $\mathrm{H}_{2}$-TPR profile is due to the reduction of $\mathrm{Co}_{3} \mathrm{O}_{4}$ to $\mathrm{CoO}[15,16]$. It was reported by $\mathrm{Zu}$ et al. that the typical $\mathrm{H}_{2}$-TPR profile of $\mathrm{Co}_{3} \mathrm{O}_{4}$ has two reduction peaks: the main reduction peak at $330-450{ }^{\circ} \mathrm{C}$ with a shoulder peak at $323^{\circ} \mathrm{C}$ [15]. The two reduction peaks of calcined $\mathrm{Ru} / \mathrm{Co}_{3} \mathrm{O}_{4}$ are all shifted to a low temperature range, and the maximum reduction peak of calcined $\mathrm{Ru} / \mathrm{Co}_{3} \mathrm{O}_{4}$ is at $250-400{ }^{\circ} \mathrm{C}$ with a shoulder peak at $245{ }^{\circ} \mathrm{C}$ (Figure 2). This may be due to the existence of $\mathrm{Ru}$, which will promote the reduction of $\mathrm{Co}_{3} \mathrm{O}_{4}$ and $\mathrm{CoO}$. Besides, a low temperature peak at around $140{ }^{\circ} \mathrm{C}$ can be ascribed to $\mathrm{RuO}_{x}$ because the catalyst did not undergo a reduction treatment.

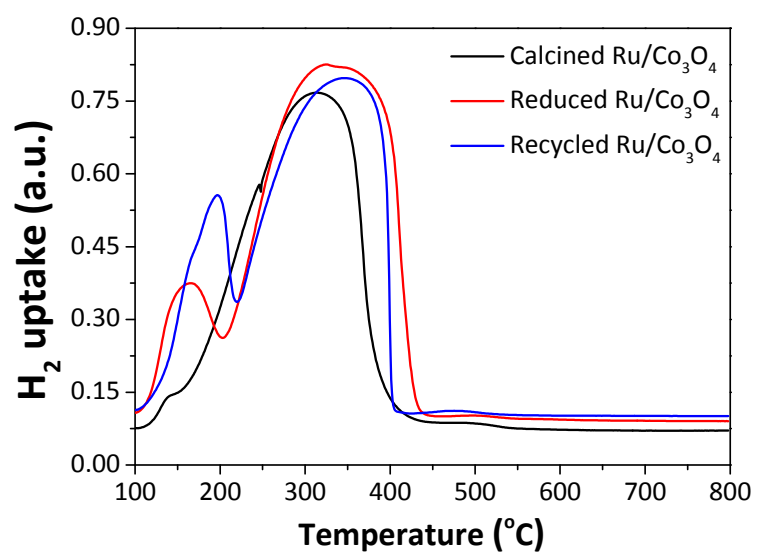

Figure 2. $\mathrm{H}_{2}$-TPR of the calcined, reduced, and recycled $\mathrm{Ru} / \mathrm{Co}_{3} \mathrm{O}_{4}$ catalysts. 
For the reduced $\mathrm{Ru} / \mathrm{Co}_{3} \mathrm{O}_{4}$ catalyst, the reduction peaks of $\mathrm{Co}_{3} \mathrm{O}_{4}$ to $\mathrm{CoO}$ and $\mathrm{CoO}$ to $\mathrm{Co}$ have shifted to a low temperature range $\left(165^{\circ} \mathrm{C}\right.$ and $200-435^{\circ} \mathrm{C}$, respectively), which is due to the presence of $\mathrm{Ru}$ [15]. The reduction peak at around $165^{\circ} \mathrm{C}$ should be the overlapping peaks for the reduction of $\mathrm{RuO}_{x}$ to $\mathrm{Ru}$ and $\mathrm{Co}_{3} \mathrm{O}_{4}$ to $\mathrm{CoO}$, indicating that the reduced $\mathrm{Ru} / \mathrm{Co}_{3} \mathrm{O}_{4}$ catalyst has the highest catalytic activity at about $165{ }^{\circ} \mathrm{C}$. These results are consistent with those in Table 1 (Entries 1-5) with respect to the effect of temperature, which showed that the highest BHMF yield was obtained at $170{ }^{\circ} \mathrm{C}$. For the recycled $\mathrm{Ru} / \mathrm{Co}_{3} \mathrm{O}_{4}$ catalyst, the first reduction peak shifts to a high temperature $\left(197^{\circ} \mathrm{C}\right)$ due to the loss of $\mathrm{Ru}$. As a result, the catalytic activity of the recycled $\mathrm{Ru} / \mathrm{Co}_{3} \mathrm{O}_{4}$ catalyst was slightly decreased at $170{ }^{\circ} \mathrm{C}$ (Table 1, Entry 8).

In addition, the reduction peak of $\mathrm{RuO}_{x}$ was absent in the reduced and the recycled $\mathrm{Ru} / \mathrm{Co}_{3} \mathrm{O}_{4}$ catalysts, which may be due to a lower $\mathrm{RuO}_{x}$ amount in the reduced and recycled $\mathrm{Ru} / \mathrm{Co}_{3} \mathrm{O}_{4}$ catalyst.

\subsection{XRD Patterns}

Figure 3 shows the XRD patterns of the calcined, reduced, and recycled $\mathrm{Ru} / \mathrm{Co}_{3} \mathrm{O}_{4}$ catalysts. From Figure 3a, it can be observed that the reflections belong to the diffraction of $\mathrm{Co}_{3} \mathrm{O}_{4}$ [17]. After the reduction with $\mathrm{NaBH}_{4}$, the intensity of the $\mathrm{Co}_{3} \mathrm{O}_{4}$ diffraction peaks is slightly lower than the calcined sample, due to the reduction of part of $\mathrm{Co}_{3} \mathrm{O}_{4}$ to $\mathrm{CoO}$ and $\mathrm{Co}$, and their reflections were confirmed in the reduced $\mathrm{Ru} / \mathrm{Co}_{3} \mathrm{O}_{4}$ sample (Figure $3 b$ ).

The XRD patterns (Figure 3c) of the recycled $\mathrm{Ru} / \mathrm{Co}_{3} \mathrm{O}_{4}$ samples are different from those of the calcined and reduced catalysts. The characteristic peaks of $\mathrm{Co}_{3} \mathrm{O}_{4}$ at $2 \theta=18.9^{\circ}, 31.3^{\circ}, 38.4^{\circ}, 44.7^{\circ}$, $55.6^{\circ}, 59.2^{\circ}$, and $65.2^{\circ}$, the peak of $\mathrm{Co}$ at $2 \theta=44.7^{\circ}$ are absent, only that at $36.5^{\circ}$ is identified (although a decrease in its intensity), indicating that $\mathrm{Co}_{3} \mathrm{O}_{4}$ have been largely reduced to $\mathrm{CoO}$ or $\mathrm{Co}$. As a result, characteristic peaks of $\mathrm{CoO}$ at $2 \theta=42.3^{\circ}$ and $61.5^{\circ}$ were evident. For all of the three catalysts, the characteristic peak of $\mathrm{RuO}_{x}$ could not be found in the XRD patterns, which is possibly due to the high dispersion of $\mathrm{RuO}_{x}$ in minute quantities.

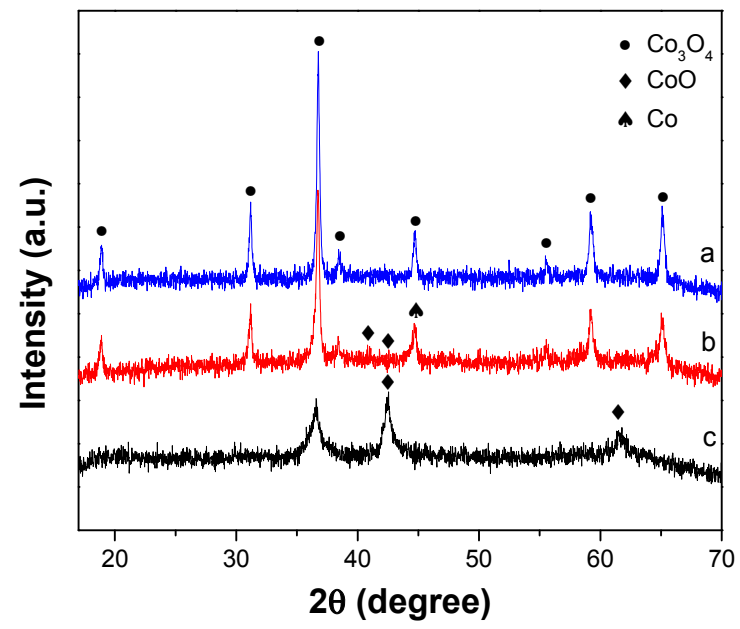

Figure 3. XRD patterns of the calcined (a), reduced (b), and recycled (c) $\mathrm{Ru} / \mathrm{Co}_{3} \mathrm{O}_{4}$ samples.

\subsection{TEM Images}

The TEM images of the reduced and recycled $\mathrm{Ru} / \mathrm{Co}_{3} \mathrm{O}_{4}$ are shown in Figure 4. The nano-platelets were formed in the reduced $\mathrm{Ru} / \mathrm{Co}_{3} \mathrm{O}_{4}$ catalyst, and the diameters of the particles are all in the range of 20-40 nm (Figure 4a). For the recycled $\mathrm{Ru} / \mathrm{Co}_{3} \mathrm{O}_{4}$ catalyst, the diameters of the particles are larger than the reduced ones, which are all in the range of 30-50 $\mathrm{nm}$ (Figure 4c). This may be due to the size aggregation in the recycling process, resulting in decreased catalytic activity (in agreement with a slightly lower BHMF yield in the presence of the recycled $\mathrm{Ru} / \mathrm{Co}_{3} \mathrm{O}_{4}$ catalyst, Table 1, Entry 8), which is in accordance with the $\mathrm{H}_{2}$-TPR observation. 
In addition, although the $\mathrm{RuO}_{x}$ particles were not found in the TEM images, the EDX analyses display that the reduced (Figure $4 \mathrm{~b}$ ) and recycled (Figure $4 \mathrm{~d}$ ) $\mathrm{Ru} / \mathrm{Co}_{3} \mathrm{O}_{4}$ catalysts do contain $\mathrm{Ru}$ (in addition to $\mathrm{Co}$ and $\mathrm{O}$ ), indicating that there is a lower $\mathrm{RuO}_{x}$ amount in the reduced and recycled $\mathrm{Ru} / \mathrm{Co}_{3} \mathrm{O}_{4}$ catalysts, which is in accordance with the $\mathrm{H}_{2}$-TPR observation. In addition, the lower amount of $\mathrm{RuO}_{x}$ particles may be highly dispersed in the matrix, so we cannot find the $\mathrm{RuO}_{x}$ particles in the TEM images [15].
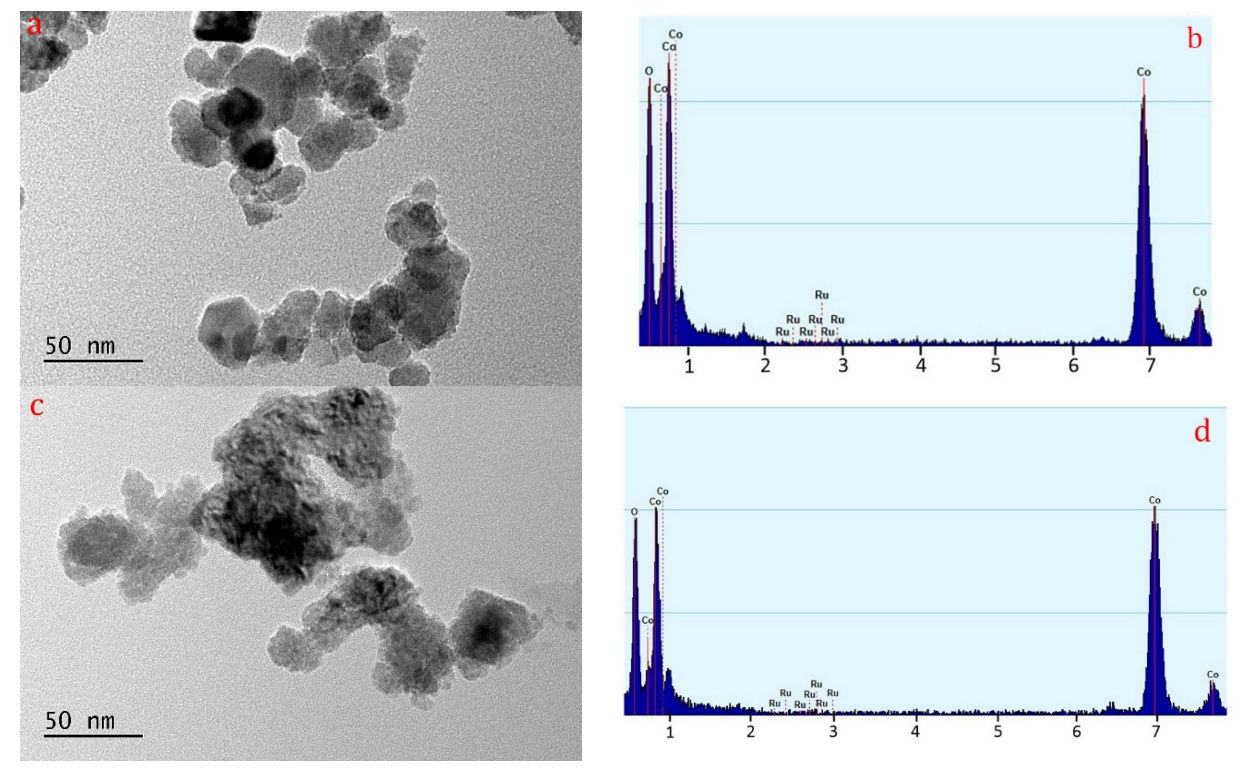

Figure 4. TEM images $(\mathbf{a}, \mathbf{c})$ and $\operatorname{EDX}(\mathbf{b}, \mathbf{d})$ of the reduced and recycled $\mathrm{Ru} / \mathrm{Co}_{3} \mathrm{O}_{4}$ samples.

\section{Reaction Processes for the CTH of HMF to BHMF}

The reaction pathways for the CTH of HMF under the conditions studied are proposed in Scheme 1 based on the published work [18]. The main steps are as follows: (1) the activation of a hydrogen donor (isopropanol) with ruthenium forms a ruthenium hydride (Reaction 1); (2) the generated ruthenium hydride will break to $\mathrm{Ru}-\mathrm{H}$ and acetone (Reaction 2); (3) Ru-H will react with a carbonyl compound $\left(\mathrm{O}=\mathrm{CR}_{2}\right)$ on HMF to yield Transition Complex I; (4) Generated Transition I will react with isopropanol through a five-membered transition state to attack the carbonyl carbon of HMF and lead to the formation of Transition Complex II; (5) the objective product, BHMF, will be generated with the elimination of ruthenium hydride, which will participate in a new catalytic cycle; (6) a small amount of BHMF can be further hydrogenated to MFA through a CTH route under very strong reaction conditions (Table 1, Entries 4-5 and 7), while no 2,5-dimethylfuran (DMF) was identified in the reaction system, indicating that the present catalytic system cannot lead to the reduction of both hydroxyl groups on BHMF under the conditions studied. This is the primary reason for the high yield of BHMF.

In addition, it was reported by Liu et al. that the etherification of the short chain alkyl alcohols would occur in the presence of Lewis acids [19]. In the present system, it is reasonable to assume that $\mathrm{Ru} / \mathrm{Co}_{3} \mathrm{O}_{4}$ may act as a Lewis acid, and the etherification products of 5-[(1-methylethoxy) methyl] furfural (MMF), 5-hydroxymethyl-2-[(1-methylethoxy)methyl]furan (HMMF), and 2,5-[bis(1-methylethoxy)-methyl]furan (BMMF) may be formed (with isopropanol). 2-methyl-5-[(1-methyletyoxy)methyl]furan (MMMF) may be formed via the CTH of HMMF and isopropanol or the etherification of MFA and isopropanol. The formation of 5-methyl furfural (MFL) may also be possible via the CTH on the hydroxyl group of HMF, and the aldehyde group of MFL can then be further hydrogenated to a hydroxyl group to form MFA. Similarly, MMF can be hydrogenated to HMMF, and HMMF to MMMF, as suggested in the literature [13]. 


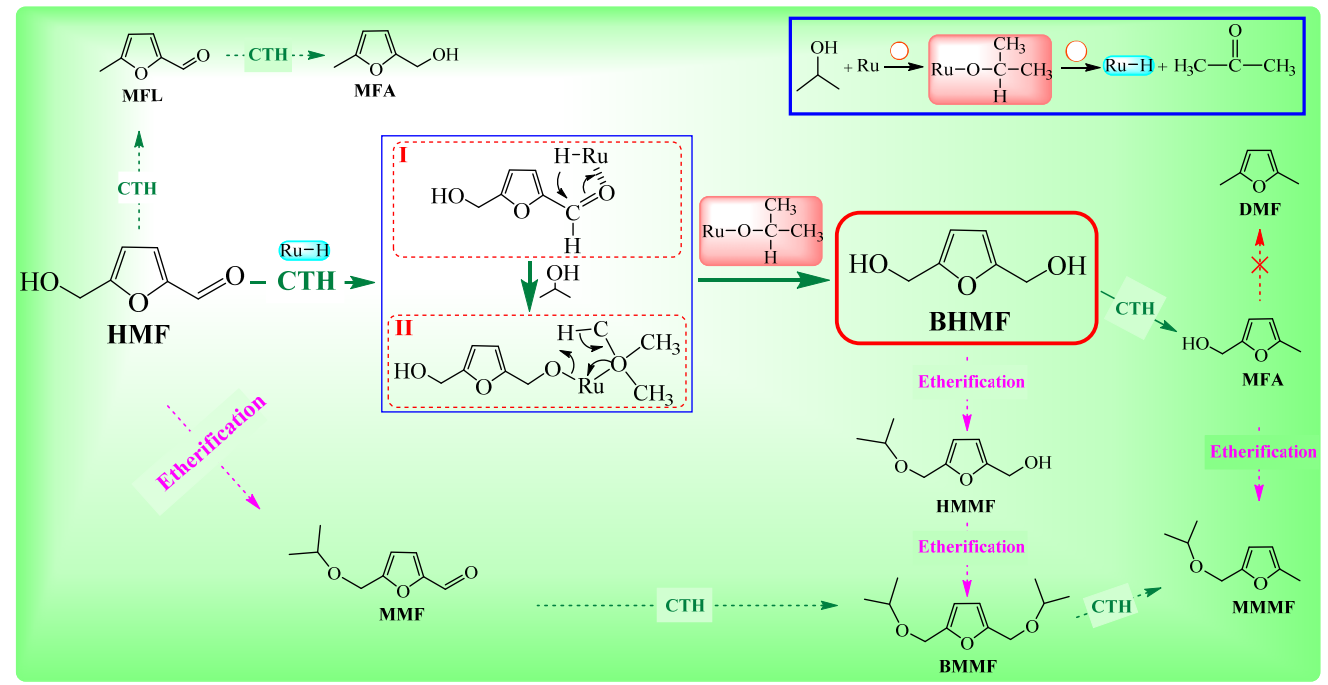

Scheme 1. Proposed reaction pathways of the CTH of HMF to BHMF using the isopropanol and $\mathrm{Ru} / \mathrm{Co}_{3} \mathrm{O}_{4}$ reaction system.

\section{Materials and Methods}

\subsection{Chemicals and Materials}

HMF (80\%) was purchased from Tengzhou Wutong Aromatizer Co., Ltd. (Shangdong, China), and $\mathrm{RuCl}_{3} \cdot \mathrm{H}_{2} \mathrm{O}$ was from Aldrich. Other chemicals and solvents, including isopropanol, $\mathrm{NH}_{3} \cdot \mathrm{H}_{2} \mathrm{O}$, $\mathrm{Co}\left(\mathrm{NO}_{3}\right)_{2} \cdot 6 \mathrm{H}_{2} \mathrm{O}, \mathrm{Na}_{2} \mathrm{CO}_{3}$, and $\mathrm{NaBH}_{4}$ were bought from Mike Chemical Instruments Co., Ltd. (Hangzhou, China). All chemicals and solvents were used without further purification. Deionized water was used for all experiments.

\subsection{Catalyst Preparation}

The $\mathrm{Ru} / \mathrm{Co}_{3} \mathrm{O}_{4}$ precursor was prepared by following a reported procedure in the literature [19]. The obtained mental oxide was reduced using $\mathrm{NaBH}_{4}$ by following a reported procedure [20]. Then, the solution was filtrated and the filtrate was dried at $50{ }^{\circ} \mathrm{C}$ for $12 \mathrm{~h}$ to obtain a $\mathrm{Ru} / \mathrm{Co}_{3} \mathrm{O}_{4}$ catalyst.

\subsection{Catalytic Activity Tests}

The CTH experiments were carried out in a $50 \mathrm{~mL}$ cylindrical stainless steel high-pressure reactor with temperature and stirring controllers. For a typical reaction, the reactor was charged with $0.5 \mathrm{wt} \%$ $\mathrm{HMF}, 0.25 \mathrm{wt} \% \mathrm{Ru} / \mathrm{Co}_{3} \mathrm{O}_{4}$ and $20 \mathrm{~mL}$ of isopropanol. The reactor was sealed, purged with nitrogen, and then heated to the prescribed temperature for a desired reaction time with stirring. At the completion of the reaction, the reactor was cooled to room temperature using cooling water. The solid catalyst was removed by filtration and recovered by calcining at $500{ }^{\circ} \mathrm{C}$ for $4 \mathrm{~h}$ and reduced by $\mathrm{NaBH}_{4}$ then dried at $50{ }^{\circ} \mathrm{C}$ for $12 \mathrm{~h}$ to get the regenerated $\mathrm{Ru} / \mathrm{Co}_{3} \mathrm{O}_{4}$ catalyst for the next use. Filtrate samples were taken for analysis on a Thermofisher Trace 1300 \& ISQ LT GC-MS instrument with a TR-5 MS column $(30.0 \mathrm{~m} \times 250 \mu \mathrm{m} \times 0.25 \mu \mathrm{m})$.

\subsection{Catalyst Characterization}

The reduction properties of the calcined, reduced, and recycled $\mathrm{Ru} / \mathrm{Co}_{3} \mathrm{O}_{4}$ were measured by means of temperature-programmed reduction $\left(\mathrm{H}_{2}-\mathrm{TPR}\right)$ techniques, and the measurements were carried out in a gas mixture of $5 \mathrm{vol} \%$ hydrogen in nitrogen at a flow rate of $30 \mathrm{~cm}^{3} \cdot \mathrm{min}^{-1}$ and a heating rate of $10{ }^{\circ} \mathrm{C} \cdot \mathrm{min}^{-1}$ from $100{ }^{\circ} \mathrm{C}$ to $800{ }^{\circ} \mathrm{C}$. The X-ray diffraction (XRD) patterns of the catalyst were recorded on a Panalytical X'pert Pro diffractometer using a $\mathrm{Cu} \mathrm{K} \alpha$ radiation source 
with the following parameters: $40 \mathrm{kV}, 30 \mathrm{~mA}, 2 \theta$ from $20^{\circ}$ to $70^{\circ}$ at a scanning speed of $7^{\circ} \cdot \mathrm{min}^{-1}$. The morphology and elemental composition of the catalyst were investigated using a Tecnai G2 20 transmission electron microscope (TEM, Tecnai G2 20, FEI, Hillsboro, OR, USA) equipped with an energy dispersive X-ray spectroscopy (EDX) unit. The TEM was operated at an accelerating voltage of $200 \mathrm{kV}$ and with a low beam current to minimize beam damage. Counting time for X-ray spectra was 15 live seconds.

\section{Conclusions}

The $\mathrm{Ru} / \mathrm{Co}_{3} \mathrm{O}_{4}$ catalyst was synthesized via a co-precipitation method and used for the $\mathrm{CTH}$ of HMF to BHMF in the presence of isopropanol. It was found that such a system displayed a high selectivity of BHMF, and the highest BHMF yield of $82.8 \%$ was obtained at $190{ }^{\circ} \mathrm{C}$ in $6 \mathrm{~h}$. The as-prepared catalyst exhibited good stability, and the recovery efficiency attained $94 \%$ at $170{ }^{\circ} \mathrm{C}$ in $10 \mathrm{~h}$. Based on the observation of the catalysts and the analysis of the oxidation products, a plausible reaction pathway of HMF to BHMF via the CTH routes was proposed. Based on the high activity, recyclability, safety, and controllability, the CTH process of converting HMF to BHMF from the present study has the potential to produce BHMF from a biomass-based precursor of HMF, which fits well with the green conversion process.

Acknowledgments: This work is financially supported by China Scholarship Council (201508330154), the Natural Science Foundation of Zhejiang province (LY17C160008), the National Natural Science Foundation of China (21406208), a China Postdoctoral Science Foundation funded project (2014M560532), the open Foundation of the Most Important Subjects in Colleges and Universities in Zhejiang Province (2015YXQN13), Zhejiang Provincial Top Key Academic Discipline of Chemical Engineering and Technology of Zhejiang Sci.-Tech. University (YR2015005), 521 Talent Cultivation Program of Zhejiang Sci.-Tech. University (11110132521309), and the open fund of the Key Laboratory of Pulp and Paper Science \& Technology of the Ministry of Education of China (KF201411).

Author Contributions: Ting Wang and Junhua Zhang conceived and designed the experiments; Ting Wang and Wenxing Xie performed the experiments; Ting Wang, Wenxing Xie, and Junhua Zhang analyzed the data; Yanjun Tang and Daliang Guo contributed reagents/materials/analysis tools; Ting Wang and Junhua Zhang wrote the paper; Yonghao Ni revised the paper.

Conflicts of Interest: The authors declare no competing financial interest.

\section{References}

1. Patel, M.; Kumar, A. Production of renewable diesel through the hydroprocessing of lignocellulosic biomass-derived bio-oil: A review. Renew. Sustain. Energy Rev. 2016, 58, 1293-1307. [CrossRef]

2. Qin, Y.; Yu, L.; Wu, R.; Yang, D.; Qiu, X.; Zhu, J. Biorefinery Lignosulfonates from Sulfite-Pretreated Softwoods as Dispersant for Graphite. ACS Sustain. Chem. Eng. 2016, 4, 2200-2205. [CrossRef]

3. Saha, B.; Abu-Omar, M.M. Advances in 5-hydroxymethylfurfural production from biomass in biphasic solvents. Green Chem. 2014, 16, 24-38. [CrossRef]

4. Cai, H.; Li, C.; Wang, A.; Zhang, T. Biomass into chemicals: One-pot production of furan-based diols from carbohydrates via tandem reactions. Catal. Today 2014, 234, 59-65. [CrossRef]

5. Timko, J.M.; Cram, D.J. Furanyl unit in host compounds. J. Am. Chem. Soc. 1974, 96, 7159-7160. [CrossRef]

6. Zeng, C.; Seino, H.; Ren, J.; Hatanaka, K.; Yoshie, N. Bio-based furan polymers with self-healing ability. Macromolecules 2013, 46, 1794-1802. [CrossRef]

7. Kang, E-S.; Chae, D.W.; Kim, B.; Kim, Y.G. Efficient preparation of DHMF and HMFA from biomass-derived HMF via a Cannizzaro reaction in ionic liquids. J. Ind. Eng. Chem. 2012, 18, 174-177.

8. Subbiah, S.; Simeonov, S.P.; Esperanca, J.M.S.S.; Rebelo, L.P.N.; Afonso, C.A.M. Direct transformation of 5-hydroxymethylfurfural to the building blocks 2,5-dihydroxymethylfurfural (DHMF) and 5-hydroxymethyl furanoic acid (HMFA) via Cannizzaro reaction. Green Chem. 2013, 15, 2849-2853. [CrossRef]

9. Zhu, Y.; Kong, X.; Zheng, H.; Ding, G.; Zhu, Y.; Li, Y.W. Efficient synthesis of 2,5-dihydroxymethylfuran and 2,5-dimethylfuran from 5-hydroxymethylfurfural using mineral-derived $\mathrm{Cu}$ catalysts as versatile catalysts. Catal. Sci. Technol. 2015, 5, 4208-4217. [CrossRef] 
10. Chatterjee, M.; Ishizaka, T.; Kawanami, H. Selective hydrogenation of 5-hydroxymethylfurfural to 2,5-bis-(hydroxymethyl)furan using Pt/MCM-41 in an aqueous medium: A simple approach. Green Chem. 2014, 16, 4734-4739. [CrossRef]

11. Yi, G.S.; Zhang, Y.G. One-Pot Selective Conversion of Hemicellulose (Xylan) to Xylitol under Mild Conditions. ChemSusChem 2012, 5, 1383-1387. [CrossRef] [PubMed]

12. Hansen, T.S.; Barta, K.; Anastas, P.T.; Ford, P.C.; Riisager, A. One-pot reduction of 5-hydroxymethylfurfural via hydrogen transfer from supercritical methanol. Green Chem. 2012, 14, 2457-2461. [CrossRef]

13. Jae, J.; Zheng, W.Q.; Lobo, R.F.; Vlachos, D.G. Production of Dimethylfuran from Hydroxymethylfurfural through Catalytic Transfer Hydrogenation with Ruthenium Supported on Carbon. ChemSusChem 2013, 6, 1158-1162. [CrossRef] [PubMed]

14. Thananatthanachon, T.; Rauchfuss, T.B. Efficient Production of the Liquid Fuel 2,5-Dimethylfuran from Fructose Using Formic Acid as a Reagent. Angew. Chem. Int. Ed. 2010, 49, 6616-6618. [CrossRef] [PubMed]

15. Zu, Y.; Yang, P.; Wang, J.; Liu, X.; Ren, J.; Lu, G.; Wang, Y. Efficient production of the liquid fuel 2,5-dimethylfuran from 5-hydroxymethylfurfural over $\mathrm{Ru} / \mathrm{Co}_{3} \mathrm{O}_{4}$ catalyst. Appl. Catal. B Environ. 2014, 146, 244-248. [CrossRef]

16. Yu, J.; Zhao, D.; Xu, X.; Wang, X.; Zhang, N. Study on $\mathrm{RuO}_{2} / \mathrm{SnO}_{2}$ : Novel and active catalysts for $\mathrm{CO}$ and CH4 oxidation. Chem CatChem 2012, 4, 1122-1132. [CrossRef]

17. Harrison, P.G.; Ball, I.K.; Daniell, W.; Lukinskas, P.; Céspedes, M.; Miró, E.E.; Ulla, M. Cobalt catalysts for the oxidation of diesel soot particulate. Chem. Eng. J. 2003, 95, 47-55. [CrossRef]

18. Guiral, V.; Delbecq, F.; Sautet, P. Origin of the Enantioselectivity in the Hydrogen Transfer Reduction of Carbonyls by a Rhodium(I) Complex: A Theoretical Study. J. Am. Chem. Soc. 2001, 20, 2207-2214. [CrossRef]

19. Xue, L.; Zhang, C.; He, H.; Teraoka, Y. Catalytic decomposition of $\mathrm{N}_{2} \mathrm{O}$ over $\mathrm{CeO}_{2}$ promoted $\mathrm{Co}_{3} \mathrm{O}_{4}$ spinel catalyst. Appl. Catal. B Environ. 2007, 75, 167-174. [CrossRef]

20. Liu, H.; Xu, J.; Zheng, Z.; Li, S.; Yao, M. Effects of fuel properties on combustion and emissions under both conventional and low temperature combustion mode fueling 2,5-dimethylfuran/diesel blends. Energy 2013, 62, 215-223. [CrossRef] 